\title{
Analisis Sentiment Tweets Berbahasa Sunda Menggunakan Naive Bayes Classifier dengan Seleksi Feature Chi Squared Statistic
}

\author{
Yono Cahyono ${ }^{1}$, Saprudin ${ }^{2}$ \\ Teknik Informatika Universitas Pamulang \\ e-mail : 1'dosen00843@unpam.com, ${ }^{2}$ dosen00845@unpam.ac.id \\ Reviewed Date: September $6^{\text {th }}, 2019$ \\ Accepted Date: October $4^{\text {th }}, 2019$
}

Submitted Date: September $3^{\text {rd }}, 2019$

Revised Date: September 16 $6^{\text {th }}, 2019$

\begin{abstract}
At present the development of the use of social media in Indonesia is very rapid, in Indonesia there are a variety of regional languages, one of which is the Sundanese language, where some people especially those living in West Java use Sundanese language to express comments, opinions, suggestions, criticisms and others in social media. This information can be used as valuable data for individuals or organizations in decision making. The huge amount of data makes it impossible for humans to read and analyze it manually. Sentiment analysis is the process of classifying opinions, analyzing, understanding, evaluating, emotions and attitudes towards a particular entity such as individuals, organizations, products or services, topics, events, in order to obtain information. The purpose of this research is the Naïve Bayes Classifier (NBC) classification algorithm and Feature Chi Squared Statistics selection method can be used in Sundanese-language tweets sentiment analysis on Twitter social media into positive, negative and neutral categories. Chi Square Statistic feature test results can reduce irrelevant features in the Nä̈ve Bayes Classifier classification process on Sundanese-language tweets with an accuracy of $78.48 \%$.
\end{abstract}

Keywords: Sentiment Analysis, Sundanese, Twitter, Nä̈ve Bayes Classifier (NBC), Chi Squared Statistic

\begin{abstract}
Abstrak
Saat ini perkembangan penggunaan media sosial di Indonesia sangat pesat, di Indonesia terdapat berbagai bahasa daerah, salah satunya adalah bahasa Sunda, di mana sebagian orang terutama yang tinggal di Jawa Barat menggunakan bahasa Sunda untuk menyampaikan komentar, opini, saran, kritik dan lain-lain di media sosial. Informasi ini dapat digunakan sebagai data berharga bagi individu atau organisasi dalam pengambilan keputusan. Jumlah data yang sangat besar membuat manusia tidak dapat membaca dan menganalisisnya secara manual. Analisis sentimen adalah proses mengklasifikasikan pendapat, menganalisis, memahami, mengevaluasi, emosi dan sikap terhadap entitas tertentu seperti individu, organisasi, produk atau layanan, topik, peristiwa, untuk mendapatkan informasi. Tujuan dari penelitian ini adalah algoritma klasifikasi Nä̈ve Bayes Classifier (NBC) dan metode pemilihan Fitur Chi Squared Statistics dapat digunakan dalam analisis sentimen tweets berbahasa Sunda di media sosial Twitter ke dalam kategori positif, negatif dan netral. Hasil uji fitur Chi Square Statistic dapat mengurangi fitur yang tidak relevan dalam proses klasifikasi Nä̈ve Bayes Classifier pada tweets berbahasa Sunda dengan akurasi $78,48 \%$.
\end{abstract}

Kata kunci: Analisis Sentiment, Bahasa Sunda, Twitter, Nä̈ve Bayes Classifier (NBC), Chi Squared Statistic

\section{Pendahuluan}

Saat ini pengguna media sosial Twitter sangat banyak. Indonesia terdapat berbagai pulau dengan beragam bahasa, pengguna media sosial Twitter di Indonesia tidak hanya penggunaan bahasa Indonesia untuk komunikasi, tapi juga penggunaan bahasa daerah seperti di daerah Jawa Barat menggunakan bahasa sunda. Perkembangan media online seperti media sosial Twitter dengan informasi yang tidak terbatas, menyebabkan kebutuhan untuk menggali informasi yang ada didalamnya. Pada Twitter terdapat istilah tweet 
yang merupakan sebuah pesan atau status yang dibuat oleh penggunanya. Sebuah tweet dapat mengekspresikan sebuah perasaan atau keadaan dari pengguna Twiter. Tweet dapat mengandung sebuah opini dari penggunanya terhadap kejadian yang dialaminya. Opini tersebut dapat dimanfaatkan sebagai penilaian baik bagi perorangan atau bagi perusahaan atau instansi.

Twitter banyak digunakan oleh instansi pemerintahan atau perusahaan sebagai media komunikasi dengan konsumen. Namun menentukan dan memilah apakah suatu tweet berbahasa sunda dapat mengandung sebuah opini positif, negatif atau netral tentu tidak mudah jika tweet yang diteliti jumlahnya sangat banyak. Maka dengan permasalahan tersebut dapat di bangun sebuah sistem yang dapat melakukan analisis sentimen.

Dari beberapa teknik klasifikasi yang sering digunakan dalam proses klasifikasi data yaitu metode Naïve Bayes atau sering disebut dengan Nä̈ve Bayes Classifier (NBC). Algoritma Nä̈ve Bayes dipilih dikarenakan algoritma ini sangat cocok untuk short data text. Kelebihan dari Nä̈ve Bayes Classifier adalah metode ini sederhana tetapi memiliki akurasi dan performansi yang tinggi dalam proses klasifikasi teks (Routray, 2013).

Sedangkan seleksi fitur adalah proses optimasi untuk mengurangi suatu set besar fitur dari sumber aslinya, agar diperoleh sejumlah subset fitur yang relatif kecil dan signifikan untuk meningkatkan akurasi dalam proses klasifikasi.

Untuk itu dalam penelitian ini menggunakan penggabungan metode pemilihan fitur Chi Squared Statistic dan Nä̈ve Bayes Classifier (NBC) untuk analisis sentiment tweets berbahasa sunda.

\section{Landasan Teori}

\subsection{Sentiment Analysis}

Sentiment analysis atau disebut opinion mining dalam pengertian secara luas mengacu pada bidang komputasi linguistik, pengolahan bahasa alami dan text mining. Secara umum, tujuannya adalah untuk menentukan attitude dari pembicara ataupun penulis yang berhubungan dengan topik tertentu.

Pengelompokkan polaritas dari teks yang ada dalam kalimat, dokumen, atau fitur entitas. Bagaimana pendapat yang disampaikan dalam kalimat, dokumen atau fitur entitas bersifat positif, negatif atau netral merupakan tugas dasar dalam analisis sentimen (Dehaff, 2010). Lebih luas lagi sentiment analysis dapat mengungkapkan emosional gembira, sedih, marah dan lain-lain.

Kita juga dapat mengetahui misalnya seperti merek, produk-produk dan orang-orang dengan menentukan apakah mereka menilai positif atau negatif. Dengan ini memungkinkan bisnis dalam melacak:
a. Persepsi produk baru.
b. Deteksi Flame (rants buruk)
c. Persepsi Merek.
d. Reputasi manajemen.

Memungkinkan juga individu untuk memperoleh mengenai suatu pandangan (review) pada skala global (Jenkins, 2011).

Sentiment atau ekspresi fokus mengacu pada topik tertentu, pernyataan pada sesuatu topik mungkin saja akan berbeda arti/makna dengan pernyataan yang sama pada subjek yang berbeda. Sebagai contoh, misalnya pernyataan yang baik untuk mengatakan "alur film tidak terprediksi", tapi lain halnya pernyataan tidak baik jika 'tidak terprediksi' dinyatakan pada "kemudi dari kendaraan tidak terprediksi". Bahkan pada produk tertentu, kata-kata yang sama dapat menggambarkan makna sebaliknya. Oleh karena itu beberapa penelitian, terutama mengenai review produk, pekerjaan dimulai dengan menentukan elemen dari suatu produk yang sedang dibicarakan sebelum dimulai proses opinion mining.

Hal utama yang dilakukan dalam pemrosesan dokumen adalah memisahkan kumpulan karakter ke dalam kata (token) atau biasa disebut sebagai tokenizing. Tokenizing adalah merupakan hal yang sangat kompleks dalam sistem komputerisasi karena beberapa karakter dapat ditemukan sebagai token delimiters. Delimiter adalah karakter tab, spasi dan baris baru/newline, sedangkan seperti karakter "! ? ( ) < >" kadangkala dijadikan delimiter namun kadangkala bukan tergantung pada lingkungannya (Wulandini \& Nugroho, 2009).

\subsection{Nä̈ve Bayes Classifier}

Algoritma Naive Bayes Classifier merupakan algoritma yang digunakan dalam mencari nilai probabilitas tertinggi untuk mengklasifikasikan data uji pada kategori yang paling tepat (Feldman \& Sanger, 2007).

Pada algoritma Naïve Bayes Classifier setiap dokumen direpresentasikan dengan pasangan atribut " $x 1, x 2, x 3, \ldots x n$ " di mana $x 1$ adalah kata pertama, $x 2$ adalah kata kedua dan seterusnya. Sedangkan $V$ merupakan himpunan pada kategori tweet. Pada saat proses klasifikasi algoritma akan 
mencari probabilitas tertinggi dari semua kategori dokumen yang diujikan $\left(V_{M A P}\right)$, di mana persamaannya adalah sebagai berikut:

$$
V_{M A P}=\operatorname{argmax}_{\frac{P\left(X_{1}, X_{2}, X_{3}, \ldots \ldots . X_{n} \mid V_{j}\right) P\left(V_{j}\right)}{P\left(X_{1}, X_{2}, X_{3}, \ldots \ldots \ldots X_{n}\right)}}
$$

Untuk $P(x 1, x 2, x 3, \ldots x n)$ nilainya konstan untuk semua kategori $(V j)$ sehingga persamaannya dapat ditulis sebagai berikut:

$$
V_{M A P}=\underset{V j e V}{\operatorname{argmax}} P\left(x_{1}, x_{2}, x_{3}, \ldots x_{n} \mid V_{j}\right) P\left(V_{j}\right)
$$

Persamaan di atas dapat disederhanakan lagi menjadi sebagai berikut:

$$
V_{M A P}=\underset{V j e V}{\operatorname{argmax}} \prod_{i-1}^{n} P\left(x_{i} \mid V_{j}\right) P\left(V_{j}\right)
$$

Keterangan :

$V j \quad=$ Kategori tweet $j=1,2,3, n$. Di mana dalam penelitian ini $j 1=$ kategori tweet sentimen negatif, $j 2=$ kategori tweet sentimen positif, dan $j 3=$ kategori tweet sentiment netral

$P(x i \mid V j)=$ Probabilitas $x i$ pada kategori $V j$

$P(V j) \quad=$ Probabilitas dari $V j$

Untuk $P(V j)$ dan $P(x i \mid V j)$ dihitung pada saat pelatihan di mana persamaannya adalah sebagai berikut:

$$
\begin{aligned}
& P\left(V_{j}\right)=\frac{\mid \text { docs } j \mid}{\mid \text { contoh } \mid} \\
& P\left(X_{i} \mid V_{j}\right)=\frac{n k+1}{n+\mid \text { kosakata } \mid}
\end{aligned}
$$

\section{Keterangan:}

$\mid$ docs $\mathrm{j} \mid=$ merupakan jumlah dokumen pada setiap kategori $j$

$\mid$ contoh $\mid=$ merupakan jumlah dokumen dari semua kategori

$n k=$ merupakan jumlah frekuensi

kemunculan setiap kata

$n=$ merupakan jumlah frekuensi kemunculan kata dari setiap kategori

$\mid$ kosakata $\mid=$ merupakan jumlah semua kata dari semua kategori

\section{Metode Penelitian}

\subsection{Pengumpulan Data (Dataset)}

Data yang digunakan untuk proses sentiment analysis ini didapatkan dengan cara crawl (mengumpulkan) data dari media sosial Twitter. Media sosial Twitter dipilih mengingat media sosial Twitter saat ini merupakan salah satu media sosial yang populer dan banyak digunakan dalam mengungkapkan pendapat atau opini mengenai sesuatu hal.

\subsection{Pre-Processing}

Pre-processing (pemrosesan awal dokumen) merupakan tahapan awal yang berfungsi dalam mentransformasikan dokumen ke dalam bentuk representasi yang lain. Tujuan dari tahap ini adalah untuk mempermudah untuk proses pencarian query ke dalam dokumen, mempercepat dalam pemrosesan terhadap dokumen, dan mempermudah dalam proses mengurutkan dokumen-dokumen yang diambil (retrieved). Tahapan proses yang dilakukan dalam preprocessing adalah casefolding, tokenize dan stopword removal (Berry \& Kogan, 2010).

\section{a. Case folding}

Pada tahapan ini dilakukan untuk pengubah huruf dalam dokumen menjadi huruf kecil. Yang diterima hanya huruf 'a' sampai dengan ' $z$ '. Sedangkan karakter selain huruf dianggap sebagai delimiter dan dihilangkan.

\section{b. $\quad$ Tokenizing}

Tahapan ini dilakukan setelah input data uji melewati tahap Case Folding. Di mana Tokenizing merupakan proses pemotongan string input berdasarkan tiap kata yang menyusunya, serta membedakan karakterkarakter tertentu yang dapat diperlakukan sebagai pemisah kata atau bukan.

c. Stopwords removal

Selanjutnya untuk tahap filter stopwords (dictionary) adalah akan menghilangkan kata-kata pada daftar stopwords yang tidak memiliki arti.

\subsection{Seleksi fitur Chi Square Statistic}

Pada penelitian ini menggunakan seleksi fitur Chi Square Statistic. Dengan cara menghitung nilai seleksi fitur Chi Square Statistic dengan persamaan sebagai berikut (Yang \& Pedersen, 1997):

$$
X^{2}(t, c)=\frac{N x(A D-C B)^{2}}{(A+C) \times(B+D) \times(A+B) x(C+D)}
$$

Keterangan:

$A$ : Banyaknya dokumen dalam kategori $c$ yang mengandung term $t$

$B$ : Banyaknya dokumen yang bukan kategori $c$ tetapi mengandung term $t$

$C$ : Banyaknya dokumen dalam katgori $c$ tetapi tidak mengandung term $t$ 
$D$ : Banyaknya dokumen yang bukan kategori $c$ dan tidak mengandung term $t$

$N$ : Total keseluruhan dokumen

Seleksi fitur Chi Square Statistic digunakan untuk melakukan kesesuaian pegamatan (goodness of fit) dari kategori dengan terms. Uji Chi Square Statistic dalam statistika diterapkan untuk menguji independensi dari dua peristiwa. Sedangkan dalam seleksi fitur berdasarkan teori statistika, dua peristiwa tersebut di antaranya adalah kemunculan fitur dan kemunculan kategori.

\subsection{Tahap Cross Validation}

Dalam tahap cross-validation, setiap record akan digunakan beberapa kali yaitu untuk data training dan untuk data testing. Untuk dapat mengilustrasikan pada metode ini, anggaplah data akan dipartisi ke dalam dua subset. Yang pertama dipilih satu subset tersebut untuk training dan satu lagi untuk testing. Kemudian akan dilakukan pertukaran fungsi dari subset sehingga subset yang sebelumnya sebagai training set akan menjadi testing set demikian sebaliknya.

10-fold cross-validation akan melakukan mengulang pengujian sebanyak 10 kali dan hasil pengukuran adalah nilai rata-rata dari 10 kali pengujian. Metode ini merupakan evaluasi standar yaitu stratified 10-fold cross-validation karena menunjukkan bahwa 10-fold cross-validation adalah merupakan pilihan terbaik untuk mendapatkan hasil validasi yang lebih akurat. Keuntungan dari metode ini adalah menghindari overlapping pada data testing. Test set bersifat mutually exclusive dan secara efektif mencakup keseluruhan data set. Namun kekurangan dari pendekatan ini ialah banyaknya proses komputasi untuk melakuan pengulangan prosedur sebanyak $N$ kali. (Gorunescu, 2011).

\subsection{Tahap Klasifikasi}

Pada tahap klasifikasi menggunakan algoritma Naive Bayes Classifier yang merupakan proses klasifikasi dengan metode probabilitas, yaitu memprediksi peluang pada masa yang akan datang, berdasarkan pengalaman pada masa lalu sehingga dikenal sebagai teorema Bayes.

\subsection{Evaluasi}

Evaluasi performansi dilakukan untuk menguji hasil dari proses klasifikasi dengan cara mengukur nilai performansi dari sistem yang telah dibuat. Parameter pengujian yang digunakan untuk evaluasi adalah diperoleh dari tabel
Confussion Matrix untuk perhitungan tingkat akurasinya,

Pada Tabel 1, untuk True Positif (TP) merupakan tupel positif di dataset yang diklasifikasikan positif, sedangkan False Positif (FP) adalah tupel positif di dataset yang diklasifikasikan negatif atau netral. Untuk True Negatif (TN) merupakan tupel negatif di dataset yang diklasifikasikan negatif, sedangkan False Negatif (FN) merupakan jumlah tupel negatif di dataset yang diklasfikasikan positif atau netral. Untuk True Netral (TNet) merupakan tupel netral di dataset yang diklasifikasikan netral, sedangkan False Netral (FNet) adalah tupel netral di dataset yang diklasifikasikan positif atau negatif.

Tabel 1 Confussion Matrix

\begin{tabular}{|l|l|l|l|}
\hline & $\begin{array}{l}\text { true } \\
\text { Negatif }\end{array}$ & $\begin{array}{l}\text { true } \\
\text { Positif }\end{array}$ & $\begin{array}{l}\text { true } \\
\text { Netral }\end{array}$ \\
\hline pred. Negatif & TN & FP & FNet \\
\hline pred. Positif & FN & TP & FNet \\
\hline pred. Netral & FN & FP & TNet \\
\hline
\end{tabular}

Selanjutnya untuk menghitung accuracy, Recall Positives, Recall Negatives, Recall Neutral, Positives Predicted Value (PPV), Negatives Predicted Value (NPV), Neutral Predicted Value (NetPV).

Accuracy $=\frac{T P+T N+T N e t}{T P+T N+F P+F N+F N e t+T N e t}$

Recall Positives $=\frac{T P}{T P+F N+F N e t}$

Recall Negatives $=\frac{T N}{T N+F P+F N e t}$

Recall Neutral $=\frac{T N e t}{T N e t+F P+F N}$

$P P V=\frac{\text { Number of True Positives }}{\text { Number of True Positives }+ \text { Nuber }}$

$N P V=\frac{\text { Number of True Negatives }}{\text { Number of True Negatives }+ \text { Number of False Negatives }}$

NetPV $=\frac{\text { Number of True Neutral }}{\text { Number of True Neutral }+ \text { Number of False Neutral }}$

Recall Positives (perolehan positif) adalah jumlah kasus dengan perolehan positif, Recall Negatives (perolehan negatif) adalah jumlah kasus dengan perolehan negaitif, dan Recall Neutral (perolehan netral) adalah jumlah kasus dengan perolehan netral. , $N P V$ (nilai prediktif negatif) adalah jumlah kasus dengan hasil diagnosa negatif, $P P V$ (nilai prediktif positif) adalah jumlah kasus dengan hasil diagnosa positif dan NetPV (nilai prediktif netral) adalah jumlah kasus dengan hasil diagnosa netral. 


\section{Hasil Penelitian}

\subsection{Implementasi Menggunakan RapidMiner}

Penelitian ini dilakukan dengan menggunakan tool rapidminer versi 5.3. Penelitian dilakukan dengan kombinasi metode atau melakukan penentuan jumlah fitur pada proses seleksi fitur. Harapan dari proses seleksi fitur ini adalah semakin sedikit jumlah fitur yang digunakan, semakin rendah waktu komputasi dan semakin tinggi akurasi yang dicapai.

Tahapan-tahapan dalam penelitian ini dapat diuraikan sebagai berikut:

a. Persiapan Dataset

Tahap persiapan Dataset ini data yang digunakan sebanyak 316 tweets, yang disimpan dalam file excel, di mana pada setiap record berisi sebuah kalimat yang mengandung bahasa sunda, namun dari data tweets yang diperoleh terdapat campuran bahasa sunda dan Indonesia. Berikut contoh tweets untuk dataset dalam penelitian ini ditunjukkan pada Tabel 2. b. Proses Klasifikasi Pada RapidMiner

Proses klasifikasi diawali dengan penentuan dataset yang disimpan di dalam file excel. Ditujukan pada Gambar 1 Penentuan Dataset.

Tabel 2 Tweets Berbahasa Sunda

\begin{tabular}{|l|l|}
\hline $\begin{array}{l}\text { persib Sakitu kituna butut, lini tukang } \\
\text { lapuk weuh harepan }\end{array}$ & Negatif \\
\hline $\begin{array}{l}13 \times \text { main } 3 \text { x menang sisanya draw } \\
\text { jeung eleh. 2019 kemunduran persib } \\
\text { pisan }\end{array}$ & Negatif \\
\hline $\begin{array}{l}\text { Tetep masih dukung persib, Erek } \\
\text { susah erek seneng tetep persib }\end{array}$ & Positif \\
\hline persib Teu ngaruh oge & Netral \\
\hline $\begin{array}{l}\text { Jauh ti dulur Jauh ti lembur Aink tetep } \\
\text { PERSIB }\end{array}$ & Positif \\
\hline kamari abi hente lalajo persib & Netral \\
\hline $\begin{array}{l}\text { Da urang mah orang Sunda nya wajib } \\
\text { we ngadukung Persib mah }\end{array}$ & Positif \\
\hline
\end{tabular}

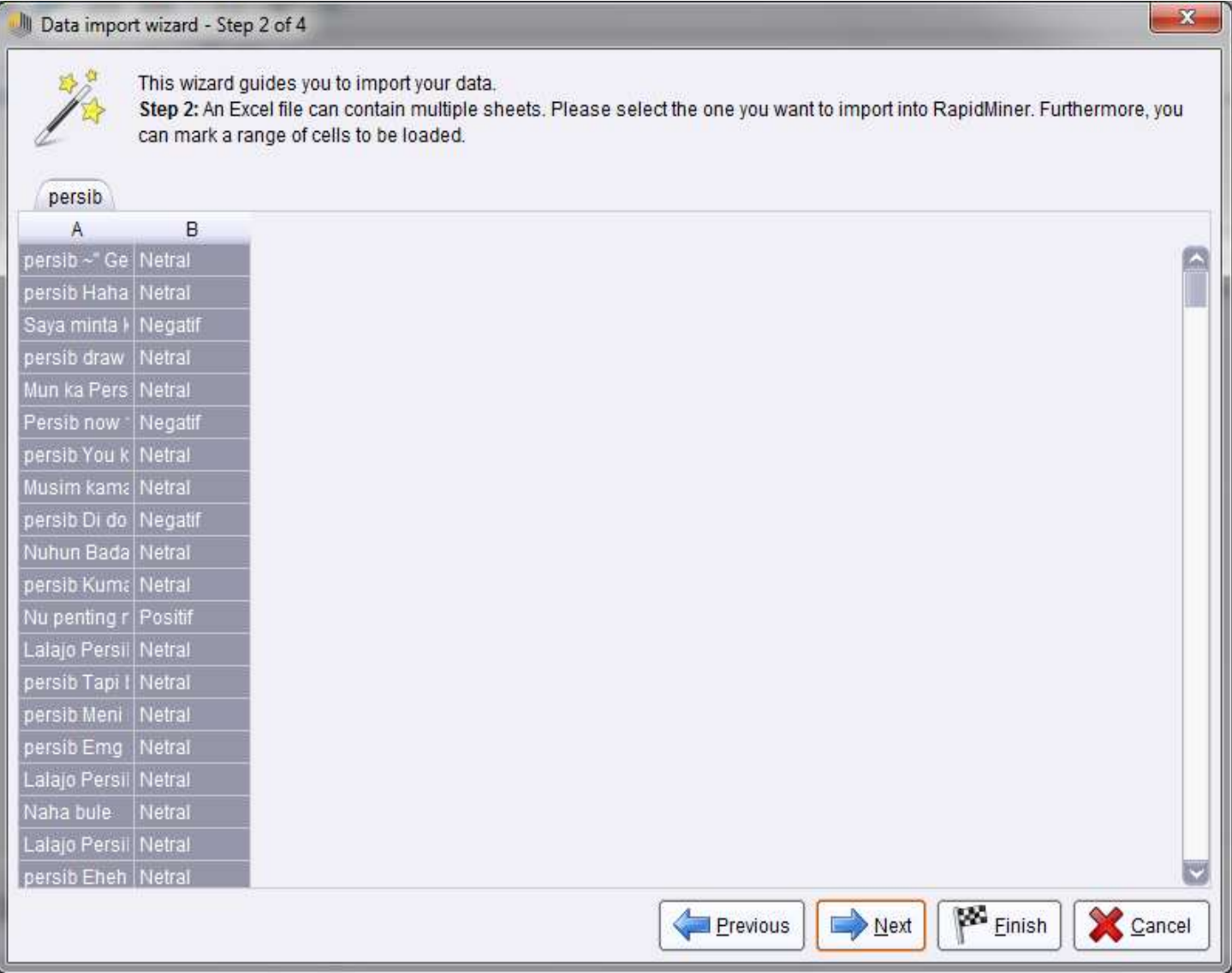

Gambar 1 Penentuan Dataset

Untuk text preprocessing ditunjukkan pada Gambar 2 Text Preprocessing yaitu dengan tahapan menggunakan transform case, tokenize, dan filter stopwords (dictionary). 


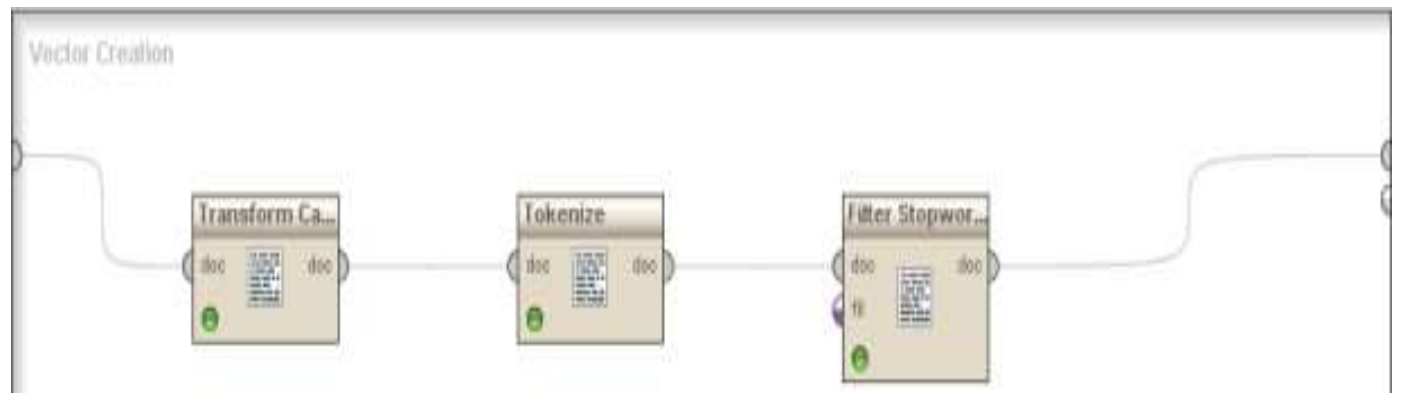

Gambar 2 Text Preprocessing

Tabel 3 Kata-kata Stopwords Bahasa Indonesia dan Bahasa Sunda

\begin{tabular}{|l|l|l|l|}
\hline ada & berapa & anu & ayeuna \\
\hline adalah & berapakah & anyar & badag \\
\hline adanya & berapalah & apa & bade \\
\hline adapun & berapapun & aranjeun & bagean \\
\hline agak & berarti & arek & baheula \\
\hline agaknya & berawal & asa & bakal \\
\hline agar & berbagai & atanapi & baruk \\
\hline
\end{tabular}

Tahap transform case dilakukan untuk merubah huruf dalam dokumen menjadi huruf kecil dan menghapus karakter simbol. Setelah melalui tahap transform case selanjutnya untuk tahap tokenize yaitu memotong setiap kata dalam teks. Selanjutnya untuk tahap filter stopwords (dictionary) adalah akan menghilangkan atau menghapus kata-kata yang tidak memiliki arti, di mana kata-kata tersebut terdapat pada daftar stopwords bahasa Indonesia dan bahasa sunda terdiri dari 999 kata-kata. Contoh kata-kata stopwords bahasa Indonesia dan bahasa sunda ditunjukkan pada Tabel 3 .

c. Seleksi fitur menggunakan Chi Square Statistic

Pada tahap berikutnya seleksi fitur Chi Square Statistic dilakukan Optimize Selection dengan menggunakan forward selection. Tahap penyeleksian fitur ini menggunakan Chi Square Statistic di mana proses ini adalah untuk memilih kata atau term apa saja yang dapat dijadikan sebagai wakil penting untuk kumpulan dokumen yang akan dianalisis. Untuk proses klasifikasi dengan seleksi fitur Chi Square Statistic ditunjukkan pada Gambar 3.

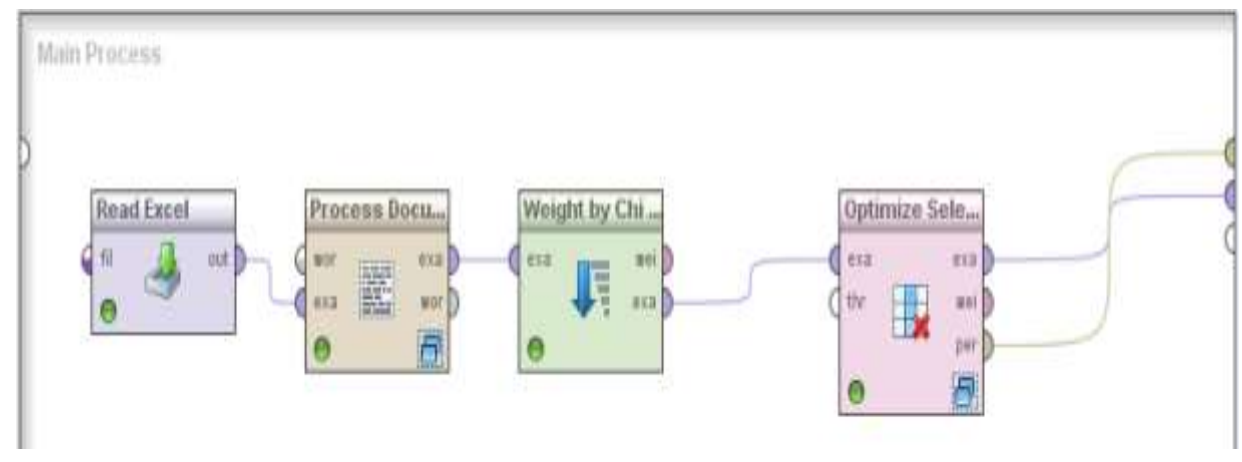

Gambar 3 Proses klasifikasi dengan seleksi fitur Chi Square Statistic

Read Excel dipakai untuk membaca dataset yang disimpan di dalam file excel. Process Documents merupakan tahap Text Preprocessing yaitu terdiri dari tahapan transform case, tokenize, dan filter stopwords (dictionary).Weight by Chi merupakan tahap penyeleksian fitur menggunakan Chi Square Statistic. Dan Optimize Selection dengan memilih parameter forward selection. Forward selection dimulai dengan tidak adanya fitur dan akan memulai menambahkan satu persatu fitur, sampai tidak ada lagi fitur yang mungkin dapat menurunkan error secara signifikan.

Cross-validation disini membagi data ke dalam dua subset, satu untuk data training dan satu lagi untuk data testing. Lalu akan dilakukan pertukaran fungsi dari dua subset tersebut, sehingga subset yang sebelumnya sebagai data training akan menjadi data testing demikian sebaliknya. 10-fold cross-validation akan 
melakukan mengulang pengujian sebanyak 10 kali dan hasil pengukuran adalah nilai rata-rata dari 10 kali pengujian. Proses 10-fold validation dilakukan untuk meningkatkan akurasi klasifikasi. Proses ini diletakan didalam proses optimize selection. Didalam proses 10-fold validation terdapat proses klasifikasi yang dilakukan oleh algoritma nä̈ve bayes seperti ditunjukkan pada Gambar 4 10-fold validation.

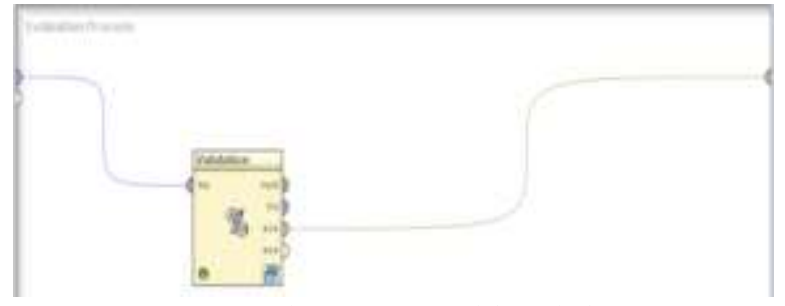

Gambar 4 10-Fold Validation

Proses klasifikasi di sini adalah untuk menentukan sebuah kalimat terklasifikasi ke dalam kategori positif, negatif dan netral, berdasarkan nilai perhitungan probabilitas naïve bayes yang lebih besar. Misal jika hasil dari probabilitas kalimat untuk kategori negatif lebih besar daripada kategori positif dan netral maka kalimat tersebut termasuk ke dalam kategori negatif. Begitu juga sebaliknya dengan kategori positif dan netral.

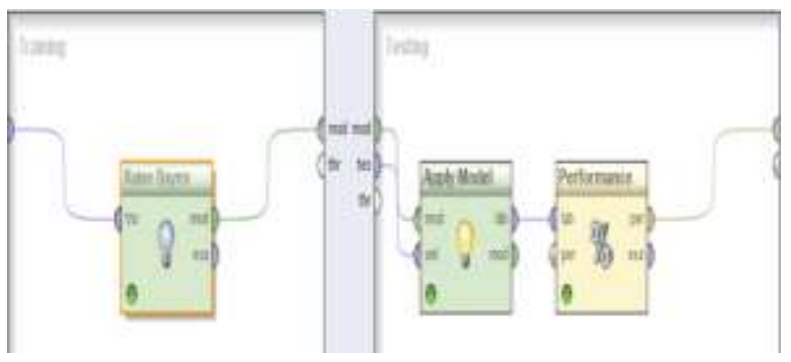

Gambar 5 Klasifikasi Nä̈ve Bayes

\subsection{Hasil Pengujian Chi Square Statistic dan Naïve Bayes.}

Tabel 4 Confussion Matrix Chi Square Statistic dan Naïve Bayes

\begin{tabular}{|l|l|l|l|}
\hline & $\begin{array}{l}\text { true } \\
\text { Netral }\end{array}$ & $\begin{array}{l}\text { true } \\
\text { Negatif }\end{array}$ & $\begin{array}{l}\text { true } \\
\text { Positif }\end{array}$ \\
\hline pred. Netral & 119 & 47 & 11 \\
\hline pred. Negatif & 6 & 98 & 1 \\
\hline pred. Positif & 3 & 0 & 31 \\
\hline
\end{tabular}

Untuk dapat mengetahui tingkat akurasi dari penggunaan seleksi fitur Chi Square Statistic dilakukan pengujian dengan perhitungan pada tabel Confussion Matrix. Ditunjukkan pada tabel 4 Confussion Matrix Chi Square Statistic dan Nä̈ve Bayes.

Pada Tabel 4 diperoleh untuk jumlah True Netral (TNet) adalah 119, True Negatif (TN) adalah 98, True Positif (TP) adalah 31, False Netral (FNet) adalah 9, False Negatif (FN) adalah 47 dan False Positive (FP) adalah 12. Berdasarkan perhitungan tingkat akurasi dari data yang diperoleh pada tabel 4, menunjukkan bahwa penggunaan seleksi fitur Chi Square Statistic dan algoritma klasifikasi Nä̈ve Bayes Classifier mendapatkan akurasi sebesar $78.48 \%$.

$$
\begin{aligned}
\text { Accuracy } & =\frac{\mathrm{TP}+\mathrm{TN}+\mathrm{TNet}}{\mathrm{TP}+\mathrm{TN}+\mathrm{FN}+\mathrm{FP}+\mathrm{FNet}+\mathrm{TNet}} \\
& =\frac{31+98+119}{31+98+47+12+9+119} \\
& =\underline{248} \times 100 \%=78,48 \%
\end{aligned}
$$

\section{Kesimpulan}

Dapat disimpulkan berdasarkan hasil analisis yang dilakukan pada penelitian ini adalah sebagai berikut:

a. Metode seleksi fitur Chi Square Statistic dan algoritma klasifikasi Nä̈ve Bayes Classifier dapat digunakan dalam proses menganalisis sentiment tweets berbahasa sunda.

b. Hasil pengujian yang dilakukan penggunaan seleksi fitur Chi Square Statistic dapat mengurangi fitur-fitur yang tidak relevan pada proses klasifikasi Naïve Bayes Classifier dengan akurasi sebesar $78.48 \%$.

\section{Saran}

Saran-saran setelah dilakukan penelitian ini adalah sebagai berikut:

a. Penelitian selanjutnya memperbaiki pengolahan dokumen, identifikasi dokumen serta mengembangkan tahap preprocessing pada dataset berbahasa sunda seperti emoticon, singkatan dan lain-lain, untuk meningkatkan proses klasifikasi dokumen.

b. Menggunakan metode pemilihan fitur lain, seperti Term Frequency x Inverse Document Frequency, Information gain, Mutual Information, Genetic Algorithm dan lain-lain, agar dapat dibandingkan hasilnya.

c. Pada penelitian berikutnya dapat dikembangkan dengan metode algoritma klasifikasi lainnya seperti Neural Network, Support Vector Machine, K-Nearest Neighbor (K-NN) dan lain-lain. 


\section{Daftar Pustaka}

Berry, M.W. \& Kogan, J. 2010. "Text Mining Aplication and theory”. WILEY : United Kingdom.

Chandani, V., \& Wahono, R. S. (2015). "Komparasi Algoritma Klasifikasi Machine Learning Dan Feature Selection pada Analisis Sentimen Review Film". Journal of Intelligent Systems, 1(1), 56-60.

Dehaff, M. 2010. "Sentiment Analysis, Hard But Worth It! '”.

Feldman, R \& Sanger, J. 2007. "The Text Mining Handbook : Advanced Approaches in Analyzing Unstructured Data”. Cambridge University Press : New York.

Ginting, H. S., Lhaksmana, K. M., \& Murdiansyah, D. T. (2018). "Klasifikasi Sentimen Terhadap Bakal Calon Gubernur Jawa Barat 2018 Di Twitter Menggunakan Naive Bayes". eProceedings of Engineering, 5(1).

Gorunescu, F. 2011. "Data Mining Concepts, Model and Techniques". Berlin: Springer.

Jenkins, M. C. 2011. "How Sentiment Analysis works in machines".

Lidya, S. K., Sitompul, O. S., \& Efendi, S. (2015). "Sentiment Analysis Pada Teks Bahasa Indonesia Menggunakan Support Vector Machine (SVM) Dan K-Nearest Neighbor (K-NN). InSeminar Nasional Teknologi Informasi dan Komunikasi”.
Ling, J., Kencana, I. P. E. N., \& Oka, T. B. (2014). "Analisis Sentimen Menggunakan Metode Nä̈ve Bayes Classifier Dengan Seleksi Fitur Chi Square”. E-Jurnal Matematika, 3(3), 92-99.

Putranti, N. D., \& Winarko, E. (2014). "Analisis sentimen twitter untuk teks berbahasa Indonesia dengan maximum entropy dan support vector machine”. IJCCS (Indonesian Journal of Computing and Cybernetics Systems), 8(1), 91100.

Routray, P., Swain, C. K. \& Mishra, S.P., 2013. "A Survey on Sentiment Analysis. International Journal of Computer Applications", Agustus, 70(10), pp. 1-8

Saputra, N., Adji, T. B., \& Permanasari, A. E. (2015). "Analisis sentimen data presiden Jokowi dengan preprocessing normalisasi dan stemming menggunakan metode naive bayes dan SVM". Jurnal Dinamika Informatika, 5(1).

Wulandini, F. \& Nugroho, A. N. 2009. "Text Classification Using Support Vector Machine for Webmining Based Spation Temporal Analysis of the Spread of Tropical Diseases". International Conference on Rural Information and Communication Technology 2009.

Yang, Y., \& Pedersen, J. O. 1997. "A comparative study on feature selection in text categorization". ICML, (hal. 412--420). 